\title{
TEORIA DOS JOGOS
}

A teoria dos jogos é uma área das ciências sociais aplicadas que se propõe estudar situações de interação entre jogadores mutuamente conscientes de que o resultado individual depende da ação dos demais. Essa área ocupa espaços e desfruta de importância em diversas disciplinas, como Economia, Administração, Sociologia, Psicologia e Biologia. Também está sendo uma ferramenta essencial para o desenvolvimento de outros campos do conhecimento, como a Economia de Empresas, Economia Política, Dinâmica Evolucionária e Economia Experimental. Marcelo Tyszler, professor da FGV-EESP e doutorando em Economia pelo Tinbergen Institute, da Universidade de Amsterdam, recomenda as seguintes obras:

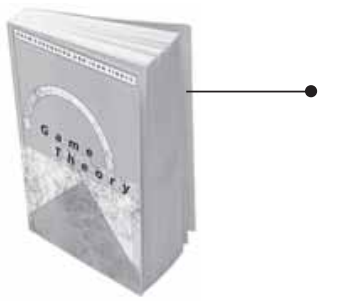

GAME THEORY. Drew Fudenberg e Jean Tirole. Cambridge: MIT Press, 1996. 579p.

A obra certamente é referência em teoria dos jogos, em particular para os cursos acadêmicos de pós-graduação. Extremamente densa e com grande preocupação com formalizações, ela é completa nos fundamentos e apresenta exercícios com elevados graus de dificuldade. No entanto, não é um livro recomendado para os não iniciados no tema e não se aprofunda em aplicações mais contemporâneas da área, apesar de fornecer os elementos para isso.

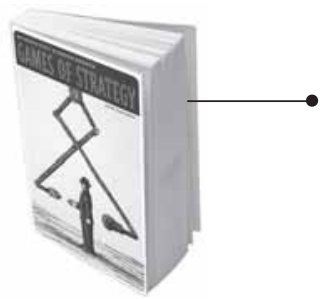

GAMES OF STRATEGY. Avinash Dixit e Susan Skeath. New York: W. W. Norton \& Compary, 2004 (2. ed.). 665p. Excelente livro para ser utilizado em graduação e pós-graduação, e indicado tanto para um primeiro contato com o tema quanto para leitores já iniciados. É um tex to bastante didático, conseguindo explicar com facilidade conceitos por vezes complexos. Em suas aplicações, traz os usos mais modernos da teoria. A limitação da obra está na falta de formalização e no baixo grau de dificuldade dos exercícios, em especial na primeira parte.

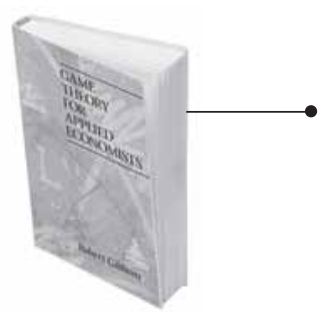

GAME THEORY FOR APPLIED ECONOMISTS. Robert Gibbons. New Jersey: Princeton University Press, 1992. 267p. M ais formal que Games of Strategy, porém de mais fácil entendimento que Game Theory, a obra pode ser considerada de nível mediano. Bem estruturada quanto aos tópicos fundamentais, preocupa-se menos com as aplicações e mais com a formalização da teoria. Apresenta bons exercícios, e é uma ótima opção como complemento de cursos de graduação mais avançados ou como base para cursos de pós-graduação.

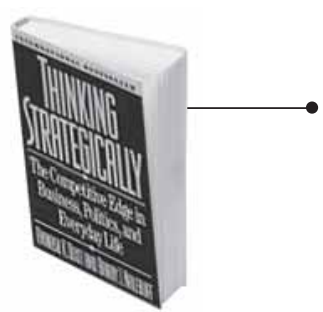

THINKING STRATEGICALlY. Avinash Dixit e Barry Nalebuf. New York: W. W. Norton, 1991. 393p.

A obra é uma das melhores introduções ao tema. Tem como público o leitor não iniciado, e explora o pensamento estratégico abordando-o com a teoria dos jogos. Introduz os conceitos básicos, tendo as situações do dia-a-dia como pano de fundo. A obra é útil em áreas da Economia A plicada, como o planejamento estratégico. Apesar de não ser um livro de teoria dos jogos tradicional, com abordagem mais teórico-formal, é indicado por trabalhar todos os conceitos essenciais.

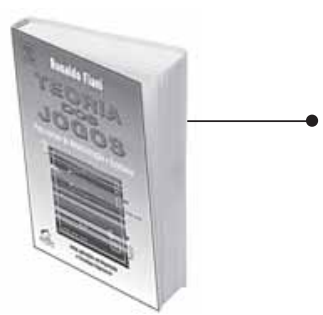

TEORIA DOS JOGOS: para cursos de Administração e Economia. Ronaldo Fiani. Rio de Janeiro: Elsevier, 2004.208p.

A obra é direcionada para cursos de graduação de Administração e Economia, com a vantagem, em relação às anteriores, de ter sido escrita em português. Procura mesclar os conceitos com notações mais formalizadas de forma introdutória. Concentra-se no desenvolvimento da teoria para aplicações de dinâmicas empresariais, como Cournot, Bertrand, Stackelberg, e de negociação, como jogos de barganha. 